\title{
Diseño en la Universidad (Premios Fin de Grado 2017-2019)
}

\author{
Javier González Solas, Javiergsolas@telefonica.net; \\ Universidad Complutense (1983-2014)
}

RESUMEN

Desde el año 2016 existe en España un Premio nacional más de diseño. Promovido por el Col.legi Oficial de Disseny Gràfic de Catalunya, ha alcanzado su tercera edición y está en marcha la convocatoria de la cuarta. El premio se denominó en un principio Premios Proyecto Fin de Grado en Diseño Gráfico y la convocatoria abarcaba las cuatro primeras promociones (2012-2015). En la convocatoria del siguiente año el nombre se asentó como Premios Gaudeamus Projecta, primeros premios estatales para los proyectos de fin de grado en diseño gráfico. En ninguna de las dos denominaciones se pone de manifiesto su especificidad universitaria, pero estos premios son una ocasión magnífica para tomar el pulso al Diseño, más que a los diseñadores. El artículo trata de las tres primeras convocatorias de los Premios $(2017,2018$ y 2019). En ellas parece que los diseñadores gozan de una excelente salud y de un estado eufórico, mientras las estructuras institucionales del diseño en las que flotan se adentran en un naufragio, al parecer, felizmente aceptado.

El discurso aquí sostenido tiene forzosamente un tinte analítico y de controversia, en cuanto que se centra en la excepcionalidad programática de los premios, en contraste con sus contenidos y resultados, pues se puede adelantar que, pese a las buenas voluntades y los esfuerzos, parecen en general acordes con la "corriente principal", que nivela e indiferencia el "mundo del diseño".

PALABRAS CLAVE

premios de diseño; estudios universitarios de diseño; mundo del diseño; capitalismo estético

ABSTRACT

Since 2016 there has been one more national design award in Spain. Promoted by the Official College of Disseny Graphic Design of Catalonia, it has reached its third edition and the call for the fourth is underway. The award was originally called the End of Degree Project Awards in Graphic Design and the call included the first four promotions (2012-2015). In the call for the following year, the name was established as the Gaudeamus Projecta Awards, the first state awards for final degree projects in Graphic design. Neither of the two denominations shows its university specificity, but these awards are a magnificent occasion to take the pulse of Design, more than designers. The article deals with the first three calls for the Awards (2017, 2018 and 2019). In them it seems that the designers are in excellent health and in euphoric state, while the institutional design structures in which they float slip into seemingly happily accepted shipwreck. The discourse held here necessarily has an analytical and controversial tinge, insofar as it focuses on the programmatic exceptionality of the awards, in contrast to their content and results, since it can be anticipated that, despite good will and efforts, they seem generally in line with the "mainstream", which levels and indifference the "world of design".

design awards; university design studies; world of design; aesthetic capitalism 


\section{Marco de los Premios Fin de Grado Relieve de los PFG ${ }^{1}$}

Habría que decir que no son unos premios al uso. Ante todo son de carácter institucional (entorno académico). No se espera que se ocupen sobre todo de poner en el candelero a unos alumnos aventajados, sino de proponer una manera distinta de hacer, de pensar, de trasformar el contexto. Si se parte del exitoso tópico "de oficio a profesión"2, habría que decir que pretenden completarlo con "de profesión a reflexión (universidad)". Lo nuclear de los estudios universitarios - o de unos premios de este nivel- no es exhibir un conjunto de trabajadores ante un mercado, como simple fuerza de trabajo, aun si fuera profesional y cualificado. Por el contrario, se exhibe y propone el fruto de un proceso de reflexión crítica para toda una sociedad, con el fin de mejorar no una profesión sino toda esa sociedad, y lograr en un momento dado su mayor funcionalidad y bienestar. Para ello se requiere una visión general, universal, "teórica", en cierto modo desinteresada y liberada: universitaria. Sin embargo, todo lo anterior no describe una realidad, sino un desideratum, hoy por hoy bastante angelical. Porque se supone que unos premios de carácter universitario deberían diferenciarse del resto de propuestas, no por un simple deseo de distinción trasnochada o arrogante, sino por una lógica división del trabajo —en este caso intelectual-o por su lugar en un entramado funcional. $Y$ también se supone que los planteamientos anteriores hubieran exigido una discusión previa acerca de ciertos conceptos sociológicos, como los de organización, función, cambio, estructura, sujeto social, etc. ${ }^{3}$, y que hubiera debido tener lugar antes de las afirmaciones y el recorrido trazado en estas líneas.

Por otro lado, limitarse a competir en la misma línea y terreno que las propuestas de otras entidades o intereses no sería un bien para la comunidad: disminuiría su diversidad y seguiría una pauta ya predefinida $-y$, en la actualidad, acrítica por lo general-, con lo que la competencia en la diversidad sería simple redundancia, y solo se podría competir en el tamaño del error.

Si se aceptase la premisa de diferenciación de identidad- de estos premios, no sería difícil

1. En este escrito, por el momento y por comodidad, se mantendrá la primera denominación, PFG, como referencia genérica. 2. Catálogo de exposición inaugural del Museu del Disseny. Vélez, P. y Calvera, A. (2014). El diseño gráfico: de oficio a profesión (1940-1980).

3. Puede encontrarse una versión relativamente conocida y adecuada en Bourdieu, P. (2000) Principios de sociología. encontrar algunas notas identitarias, aunque definirlas y llevarlas a su rendimiento pudiera resultar menos fácil, no en sí, sino por la vigilancia y constancia requeridas hasta su implantación y rodaje.

Lo que tal vez se debería considerar, al menos una vez en el transcurso de la existencia de los premios FG, no es ni siquiera su posible acomodación mimética a un modelo preexistente, sino la razón de su propia existencia. En este sentido este discurso no se ceñirá al momento terminal del acto de concesión de los premios, sino a todos sus componentes y a su trayectoria prevista. Desde el punto de vista metodológico convendría desplazar el foco sobre lo evidente hacia lo que una hermenéutica negativa podría mostrar como no inmediatamente visible: no reparar solo en lo hay, sino también en lo que no hay pero podría haber. Por ejemplo, convendría analizar el motivo y el lugar de su origen, la coherencia de los procesos, el sistema de evaluación de los resultados o el seguimiento temporal de todo el conjunto..., a la vez que hipotetizar sobre alternativas u oposiciones no previstas o no consideradas. Incluyendo el eventual momento de su cese por incompetencia o por contradicciones en el sistema, o el de su continuación por el afianzamiento de su utilidad pública. Por lo dicho, las siguientes líneas intentan orientarse en este sentido crítico (universitario), es decir, de juicio sobre un sistema institucional total, en el que se inscriben los premios como sanción y modelo para un aspecto o sector de una sociedad. O sea, la situación y función de los premios dentro del "circuito institucional" del diseño. Por eso el discurso general y global, bastante inusual en la literatura del diseño (no solo nacional), intenta prevalecer y cobrar relevancia frente a los elementos individuales y personales.

\section{Origen y antecedentes de los Premios}

Los Premios Fin de Grado nacen en 2015, en el seno del Col.legi Oficial de Disseny Gràfic de Catalunya, creado en $2003^{4}$. Su entorno remoto -y no por ello menos determinante-, es el movimiento sobre la institucionalización y regulación del Diseño. Esta presión surge fuera del campo académico, y es un caso claro de imposición de la "sociedad civil" a una institución que no lo había contemplado desde sus inercias ya establecidas y sedimentadas. En esta frase hay varios

4. Ley $11 / 2003$, de 13 de junio, de Creación del Colegio Profesional de Diseño Gráfico de Cataluña (Ley 11/2003, de 13 de junio, de Creación del Colegio Profesional de Diseño Gráfico de Cataluña. («BOE» núm. 171, de 18 de julio de 2003, páginas 28096 a 28097). 
términos plurívocos, incluso equívocos y posiblemente ideológicos (interesados) que convendría aclarar $^{5}$. La línea histórica del Diseño comienza con "su prehistoria" en la época de la revolución industrial y de las revoluciones sociales, y esto marca la definición genética de una actividad que ha pasado la mayor parte de su recorrido sin conocer sus orígenes, y sin gobernar su desarrollo -y decadencia - posterior. El paso de la modernidad a la postmodernidad y del capitalismo industrial al postcapitalismo ha conformado una estructura social en la que la sociedad civil se ha indiferenciado como elemento público y político, progresivamente diluida en democracias formales, globalizadas y populistas, lo que se suele denominar la "corriente principal"6.

En esa corriente se ha insertado tanto la multiplicación del diseño como amplio estrato laboral - paulatinamente convertido en ejército de reserva-, como el acceso multitudinario a los llamados estudios superiores.

Un entorno menos remoto del Col.legi es el de la reorganización de los estudios universitarios en el panorama europeo (Plan Bolonia). Este proceso ha tenido al menos dos consecuencias notables para la situación del diseño que se va a analizar: por un lado, la supuesta extensión y dignificación de un nuevo y pujante estrato laboral — de blue collar con apariencia de white collar- parece haber rebajado la intensión y el nivel de exigencia crítica, sobre todo en áreas de pensamiento directivo (no instrumental), que se extenderá de manera paralela por todo el sistema universitario ${ }^{7}$. Y por otro, el carácter fundacional en que se han normatizado

5. Estas premisas son fundamentales, pero este no es el momento ni lugar de aclararlas, por lo que convendría remitirse a textos ya publicados: González Solas, J. (2014) "Antes del diseño". Icono 14. -(2020) "Grupo 13: Una exposición invisible: ‘Publicidad entre el arte y el diseño', I y II" . Questiones Publicitarias, n, ${ }^{\circ} 25$. - (2020) "La quiebra histórica de la identidad del diseño". III Simposio de la FHD, Barcelona. Ver otras propuestas interpretativas en: [dialnet.unirioja.es/servlet/autor?codigo=881900] 6. Los términos corriente principal y mundo del diseño son ampliamente utilizados en la literatura sobre la postmodernidad y sobre las instituciones. El término "circuito" del diseño, es una variante aplicada al diseño: González Solas, J. (2012). "El circuito del diseño", Cinco miradas sobre el diseño.

7. La popular objeción de que el carácter universitario descrito no se puede exigir en un simple Grado, sino en el Postgrado (doctorado, máster...), es sólo nominalista, un juego de palabras. Se ha llamado ya la atención sobre cierta presión social que ha llevado a una homologación o redistribución de titulaciones entre la Formación Profesional (y similares) y la Universidad. Pero -argumentando también desde las palabras-, por una parte, los Grados no dejan de ser "universitarios", y por otra, las características propuestas más adelante como universitarias (epígrafe 4.1.) podrían ser objeto, no de títulos, sino de cualquier conocimiento "superior", e incluso deseables para cualquier miembro de una comunidad. Obviamente, no se habla de una realidad. los estudios de diseño, sobre todo en España (decidido por doce facultades de Bellas Artes $^{8}$ y establecido casi totalmente en ese entorno: ESAD's, EAD's...), parece haber marcado expectativas que configuran y encierran la actual situación del diseño en el "círculo del arte".

En síntesis: la confluencia entre el proyecto societario descrito y las necesidades ${ }^{9}$ configuradas por el sistema neoliberal muestran una gran coherencia, con pocas fisuras para vislumbrar alternativas. Escritos y reflexiones recientes, y ya no tanto, hablan de "políticas de la belleza", de "capitalismo estético", de "empresariado estético" o de "industrias creativas" -en lugar de industrias culturales-, donde se refleja una situación aceptada con complacencia por el sector del diseño, sea universitario o $\mathrm{no}^{10}$. Sin embargo, ante ese frente común pueden describirse aún algunas alternativas, aunque sean poco contempladas por las razones descritas, e incluso con pocas perspectivas de su puesta en práctica en el corto plazo. Esta última consideración no obsta para que se indaguen, sobre todo en el terreno universitario.

\section{El sistema y el lugar de los PFG ${ }^{11}$}

El modelo de discurso adoptado en estas líneas es de tipo institucionalista, suficientemente neutro e incluso escéptico como para no suscitar de momento recelos ideológicos. El sistema social se consolida en instituciones concretas, que en general actúan como fondos de convivencia aceptados y como depósito de la memoria social ${ }^{12}$. Desde una perspectiva estructuralista todos los elementos institucionales forman parte de un sistema (más allá del individuo), que en este caso compone el circuito del diseño ${ }^{13}$ : Academia, Profesión, Difusión, Sanción, Memorialización... y Crítica, que tiene una función prevalente que permea todo el sistema, y que, en cuanto análisis, discernimiento y juicio, tiene su lugar de partida y referencia en la Academia. Los Premios se sitúan en el lugar institucional de la Sanción, como un eslabón de

8. Centrado en la homologación de los estudios de Grado en la UE: ANECA (2004). Libro Blanco. Títulos de Grado en Bellas Artes/Diseño/Restauración.

9. Heller, Á. (1996). Una revisión de la teoría de las necesidades. 10. "El lobo se vestía con piel de cordero y el rebaño consentía el engaño". (Frankenstein o el último hombre). Con solo 20 años Mary Shelly escribió esta conocida frase. Murió en 1851, año de la primera Exposición Universal "de diseño",

11. En este escrito, por el momento y comodidad, se mantendrá la primera denominación, PFG, como referencia genérica.

12. Douglas. M. (1996). Cómo piensan las instituciones.

13. González Solas, J. (2016). "El diseño como industria creativa: una dudosa moneda de cambio". Informe sobre el estado de la cultura en España 2016. 
la cadena de instituciones que forman un "estado del diseño"14. Todos los eslabones del circuito son importantes y tienen su campo específico, todos en cierto modo tienen un ADN común, pero a la vez tienen rasgos de los otros campos. La crítica, por ejemplo, podría ser el descriptor básico y circulante, aunque su lugar más expresivo sería la Academia. La importancia de los Premios se expresa también en su repercusión en los otros campos del circuito ${ }^{15}$. Su carácter fundamental es la ejemplaridad, por la que podrán pasar también a formar parte del sedimento memorial. Desde estos supuestos se puede hablar de los Premios, no solo como un acto festivo, emotivo o celebratorio sino como una parte del sistema edificador del Diseño.

El Col.legi Oficial de Disseny Gràfic de Catalunya (único en el estado español) y sus Premios, se insertan en este punto de manera un tanto polémica y controvertida, aunque decidida a establecer un rasgo de seriedad en esta profesión un tanto desconfigurada, y desasistida de instituciones nacidas a la manera convencional y tradicional. Un colegio es una formación muy antigua, intermedia entre la Academia (garantiza un saber) y la Profesión (cuida su práctica y deontología), que establece una comunión de colegas. En términos de Tönnies, el Col.legi pertenecería más al tipo comunidad (Gemeinshaft) que al de sociedad (Gesellshaft). Sin embargo, al crearse en este caso concreto como una señal de presencia social, más simbólica y aspiracional que urgente y necesaria, su devenir ha debido ser combativo y atento a las circunstancias objetivas de cada momento. Los PFG podrían entenderse como signo de esa mediación entre la Academia y la Profesión.

Otras formas de organización del gremio, las asociaciones, han surgido antes y después del Colegio, en una marea de presencia pública propia del estreno democrático. Primero con carácter nacional y referencial (ADP, AEPD), luego definidas por su ámbito regional y con miras a la obtención de recursos (económicos) autonómicos, y finalmente, tras la dispersión atomizadora y mimética parece haber vuelto de nuevo la tendencia reagrupadora en búsqueda de una nueva unidad, de momento más reproductiva que productiva.

En principio un colegio debería ser único y territorial, mientras que las asociaciones podrían ser

14. Un recorrido reciente del estado del diseño en España se puede encontrar en González Solas, J. (2016). "El diseño como industria creativa: una dudosa moneda de cambio". Informe sobre el estado de la cultura en España 2016.

15. González Solas J."Yo confieso. Premios AEPD". Boletín AEPD n. ${ }^{\circ} 14$ diversas y variadas, tanto en proyectos como en tendencias y objetivos. Pero, de nuevo, la juventud institucional (tras un parón de 40 años), parece haber hecho confluir la bisoñez, el mimetismo organizativo y la imprevisión, con la precipitación de variados acontecimientos societarios ya aludidos, y acogidos a la "corriente principal" y a la "postmodernidad vulgar"16. De ahí que tanto el Col.legi (único) como el resto de estructuras asociativas se hayan encontrado y pacificado bajo las vicisitudes de tipo general y sociopolítico esbozadas, o (en escasas ocasiones), se hayan visto desbordadas por el conflicto entre el querer y el poder ${ }^{17}$.

\section{Descripción de los PFG}

\section{Datos generales}

Los primeros premios se convocan en 2016, para las cuatro primeras promociones egresadas del Grado Universitario, y a partir de ahí se establece un ritmo anual ${ }^{18}$.

Siguiendo la tónica de la mayoría de los premios, los PFG tienen aún un carácter celebratorio, promocional, publicitario, sin dejar de lado el carácter ejemplarizante general de toda sanción. Pero también podrían trascender hacia una exhibición ejemplarizante de la enseñanza universitaria y de sus criterios de evaluación. Y este es un punto crucial y polémico que se desarrollará a continuación.

La Tabla1 muestra el número de trabajos admitidos en cada convocatoria. La diferencia con los presentados es mínima, pues ya habían pasado un primer filtro con las garantías de cada centro y de sus tutores, con lo que sólo se excluía alguno que no se ajustaba a los requerimientos de la convocatoria.

El Col.legi suministraba un sistema de apoyo en el cual, más allá de las formalidades usuales (requisitos académicos, formato, fechas, Jurado...), ofrecía un formulario muy detallado y estructurado para facilitar la evaluación de los eva-

16. El término/postmodernidad/ está tan integrado en el lenguaje común que hace pasar desapercibido su carácter equívoco e ideológico, entendiéndolo de manera dominante como "positivo". El adjetivo /vulgar/ alude a acepción general, que oculta y se opone a la postmodernidad "filosófica", entendida como una corriente crítica del saber tras la esperanza moderna. La literatura básica es abundante. Habermas, J. (1989) El discurso filosófico de la modernidad puede ser una guía general. Pasa revista a esa travesía desde Kant, pasando por Hegel, Nietzsche, Horkheimer, Adorno, Heidegger, Derrida, Bataille, Castoriadis o Luhmann, (desde la filosofía hasta la sociología política), en búsqueda de un consenso sobre la verdad y la certeza. Habermas añade su propia oferta comunicativa, en la línea práctica de Marx (práxis), como medio realista e intrahumano de trabajar y estar en el mundo.

17. Más precisiones en González Solas, J. "La quiebra histórica..." (cit.).

18. No es fácil determinar la representatividad de los datos, pero parecen suficientes y significativos para una primera apreciación. 
luadores y la contabilización de los resultados, revisado tras cada convocatoria.

La misma Tabla 1 ofrece una distribución geográfica de los concursantes, donde aparece una gran concurrencia de centros de la región catalana, junto a indicios de un leve decaimiento en la afluencia en el corto periodo de tiempo considerado, y a cierta oscilación de los datos, que habría que ponderar y afinar (con una serie temporal más larga), en relación con el número total de centros y su distribución regional, la facilidad de acceso, la difusión y promoción acumulada, etc.

El Jurado se componía de varios tipos de miembros: los nombrados por el Col.legi en número variable cada año $(20,22,28)$, los miembros de derecho (la Junta Colegial (13), y el Comité Organizador (3). Aunque enseguida se comentará el sistema y los pormenores de estos datos, se puede observar ya el llamativo número de jueces.

También puede resultar significativo el volumen de los trabajos. Sin atender a la proporción de texto literario e icónico, llama la atención también la obligada lectura de unas 8.000 páginas en el espacio de un mes (por lo general en periodo convencional de vacaciones), con la posterior precisión en los protocolos de calificación... Sin contar con la frecuente desproporción entre volumen e interés de cada trabajo. En los datos puede verse también la media de páginas por trabajo y año (unas150 páginas), con un mínimo de 22 páginas (en un único trabajo, sin embargo serio y provocativo: sin imágenes y en courier!), y un máximo de 466 . Estas cifras adquirirán su verdadero valor más adelante, cuando se trate de la lógica de la cantidad, o del "efecto despiste" entre un abrumador marco introductorio y los resultados concretos.

Aunque los datos del análisis anterior corresponden a las tres primeras convocatorias, la continuidad metodológica y los resultados obtenidos en las dos siguientes confirman la validez del juicio, diagnóstico y pronósticos señalados por el autor ya en la primera convocatoria ${ }^{19}$.

19. El Decano del Col.legi, con un criterio que perseguía unas pautas razonables para siguientes convocatorias, y obtener un instrumento para el debate y posterior afinación de la personalidad y exclusividad de los Premios, propuso a los miembros del Jurado la explicación de los criterios de evaluación de cada uno, así como las sugerencias y propuestas oportunas. Pretendía recogerlas en una publicación que dejase constancia de lo excepcional del Premio y que funcionase como documento para el debate sobre su sentido, su transparencia metodológica y su carácter diferenciador. Por diversas circunstancias esta posibilidad se desvaneció y quedó reducida a este testimonial y personal artículo. También pudo ocurrir que, de manera coyuntural, el Col.egi desviase su esfuerzo hacia aspectos administrativos o de mecánica de los procesos, más que hacia la construcción conceptual.

\begin{tabular}{l|c|c|c}
\hline \multicolumn{4}{l}{ Tabla 1. Datos convocatorias PFG } \\
\hline Trabajos/año & 2017 & 2018 & 2019 \\
\hline Zona & \multicolumn{3}{l}{} \\
\hline Catalunya & 40 & 27 & 28 \\
\hline Madrid & 4 & 14 & 7 \\
\hline Resto & 17 & 13 & 7 \\
\hline Total & $\mathbf{6 1}$ & $\mathbf{5 4}$ & $\mathbf{4 2}$ \\
\hline
\end{tabular}

\begin{tabular}{l|c|c|c}
\hline \multicolumn{5}{l}{ Tabla 2. Jurados } \\
\hline Años & 2017 & 2018 & 2019 \\
\hline Designados & 20 & 22 & 28 \\
\hline Junta Col. & 13 & 13 & 13 \\
\hline Comité organiz. & 3 & 3 & 3 \\
\hline Total & $\mathbf{3 7}$ & $\mathbf{3 9}$ & $\mathbf{4 7}$ \\
\hline
\end{tabular}

\section{Preanálisis y crítica del contexto}

Antes del dictamen sobre el conjunto de todo el proceso conviene hablar de su contexto, ya que algunas circunstancias condicionan el sentido tanto de los datos como de sus consecuencias y valoraciones.

\section{Identidad y contexto}

La perspectiva de la identidad corporativa puede ser un marco adecuado para este caso, sobre todo si, más allá de las rutinas habituales y escolares del sector, se toma en consideración todo el sistema social que la rodea y el lugar ocupado por el diseño y sus instituciones.

La identidad se entiende ante todo como un acto y un hecho social, que termina y se determina en una coyuntura actual. Más allá del modelo de celebración puntual al uso, conviene considerar no solo la identidad del propio acto $^{20}$ (de diseño) sino su contexto próximo (peri-texto), que enlaza las funciones y el trabajo atribuido a una entidad con el contexto general público (político) de una sociedad civil en un tiempo concreto.

Algunos de los elementos que intervienen en la configuración de los atributos de los PEG son, por ejemplo, la entidad convocante (un Colegio), su

20. Actos de diseño: González Solas, J. (2012). "Hechos de diseño". Cinco miradas sobre el Diseño. JGS ed. p. 345-361 


\section{Tabla 3. Composición Jurado}

\begin{tabular}{l|c|l|l}
\hline Años & 2017 & & \\
\hline Profesión & 10 & & \\
\hline Universidad & 7 & & \\
\hline Industria & 3 & & \\
\hline
\end{tabular}

1. Los datos corresponden a la primera convocatoria. En ella pareció interesante buscar alguna estructura dentro de la mayoría profesional: a grandes rasgos pareció que en unos profesionales parecía dominar la práctica universitaria, y en otros la práctica profesional, con eventuales intervenciones en la universidad. Con el paso de las convocatorias tal intención distintiva ha parecido irrelevante frente al conjunto de problemas que se muestran en los Jurados en general.

\section{Tabla 4. Volumen de los trabajos}

\begin{tabular}{l|c|c|c}
\hline Años & 2017 & 2018 & 2019 \\
\hline Páginas & 8.294 & 8.572 & 6.082 \\
\hline Por trabajo & 140 & 158 & 144 \\
\hline
\end{tabular}

horizonte espacio-temporal (nacional, centros universitarios), su sector de actuación (diseño "gráfico"), sus sistemas de control (premios, jurados, escuelas, tutores)... puntos a considerar para encontrar las posibilidades de maniobra fuera de los hábitos marcados por el lugar y las inercias. También se aprecia cómo este eslabón del "circuito" puede extender su carácter (Sanción) hacia todo el sistema. Y cómo la identidad de los Premios es, por tanto, un elemento fundamental de su sentido — ¿misión?- y efectividad a largo plazo. Sería útil aplicar a cada elemento con potencial identitario el criterio de la hermenéutica negativa: ver lo que hay e imaginar lo que no se ve, (puntos ciegos, tal vez programados) para visibilizar un panorama universal (universitario).

Sólo se tratarán algunos de ellos, los más relevantes o los más patentes y clamorosos en los datos anteriores.

Entidad convocante. No se debe pasar por alto que quien convoca es un Colegio Profesional, con las características propias de estas instituciones, obligado tal vez (por ser único) a una sobre-representación asumida de manera voluntarista y coyuntural, que ahora no es el caso de tratar.

Diseño Gráfico. Es obvio que se trata de un elemento reductor del ámbito del diseño, al igual que la territorialidad colegial, con lo cual parece natural que tienda a suplir su solitaria unicidad y a solapar las carencias de otras instancias, con un posible desenfoque de su propio contorno.

- En la indefinición actual de fronteras, la división técnica entre DG, DI y DE, puede dificultar una focalización precisa sobre estos Premios.

- El desenfoque terminológico y distributivo producido en los últimos años (deriva hacia la "creatividad", poco reflexionada pero aceptada por el gremio ${ }^{21}$ ) es otro problema de identidad genérica.

- El reducto a "lo gráfico" puede tender a ser compensado sobredimensionando su papel, sobre todo mediante la sobreestetización llevada a otros sectores.

- Más importante aún resulta admitir el hecho de que el DG (de Comunicación) se comporta frente al mundo objetual (Diseño Industrial y Diseño Espacial) $)^{22}$ como un descriptor simbólico, como un lenguaje dado a las cosas. Es decir, que en el actual estatuto de las relaciones sociales el DG se comporta como legitimador del diseño objetual.

- De igual manera, sus autolimitaciones pueden derivar también de su "minihistoria", interpretada sin réplica ni contraste como historia del "diseño puro" (lo gráfico) frente al diseño "impuro" de la comunicación (la publicidad, los medios...), enmascarando así el resto de impurezas y complejidades ideológicas y políticas existentes en un mundo exterior y real ${ }^{23}$.

Una conclusión de esta situación puede ser que la identidad no puede ya hacer distinción lógica —ni estratégica ni teórica (universitaria)— entre sectores (lógicas funcionales e instrumentales), si se acepta que todos ellos se encuentran hoy sometidos a la disciplina de una única lógica hegemónica, heterónoma, común y globalizada:

21. Ver Informe sobre el estado de la Cultura 2016 (cit.). De hecho la UE ya hace años que ha aceptado el término como focalizador de sus trámites (UE (2011): Programa Europa Creativa. Consejo de la Unión Europea. Bruselas). Los ministerios y consejerías españoles han hecho lo propio (Ministerio de Cultura y Deporte (2018): Plan de fomento de las industrias culturales y creativas 2018). Con reflejos también en la reciente entrega de los Premios 2019: presentes la "Dir. Gral. de Creación, Acción Territorial y Bibliotecas", la "Regiduría de Turismo e Industrias Creativas", y los constantes titulares mediáticos lanzados bajo la denominación de "industrias creativas"...

22. Hoy cambiados de forma significativa hacia diseño de "producto" y diseño del "entorno".

23. Lorés, J. "Grafismo puro, grafismo impuro". Revista CAU. n. ${ }^{\circ}$ 9, 1971. Sin embargo hoy el DG significa por antonomasia el carácter retórico de toda comunicación postmoderna: una vez que el lógos se ha trasformado en éthos y en páthos, es decir en retórica persuasiva. También aquí se aprecia el reflujo, la incipiente corriente centrípeta y cohesiva que se ha señalado en el asociacionismo: de manera aún poco notoria se aprecian intentos de redefinir el DG como Diseño de Comunicación: ¿un principio de alejamiento de su herencia Beaux Arts? 
una lógica postpolítica y postmoderna. La consciencia de este factor de identidad no parece haber asomado aún en los movimientos estratégicos ni tácticos de las estructuras simplemente funcionales e inerciales del diseño.

Jurado. La constitución del Jurado es una función identitaria fundamental. El Jurado descrito se podría calificar de desmedido, en vías de resultar incluso multitudinario. Es el tipo más general e imita$\mathrm{do}^{24}$, a pesar de que se podría con facilidad establecer una diferencia con otros jurados y premios, sobre todo por su carácter de "objeto universitario". Se ha sugerido ya la dificultad de configurar un Jurado adecuado, que, más allá del rédito logrado por cada uno de los jueces o por la institución (en forma de reconocimiento, de promoción personal o de prestigio por contaminación, típicos de una relación comensalista fuera de lugar), manifieste una oferta conceptual de trabajo y de hipótesis, específica y razonada. Sin embargo, de entrada manifestaría ya una identidad y una especificidad del proyecto, de su coherencia, de sus metas y de sus consecuencias para la esfera pública ${ }^{25}$, más allá de lo privado. De ahí el interés de la iniciativa (fallida) de pedir, al menos ex post, una exposición y debate de los criterios del Jurado. Sería una aportación al enriquecimiento de un campo, el del llamado diseño, que ya ha dado muestras, como mínimo, de languidez ${ }^{26}$. Con esto no se intenta dar una solución-receta, sino poner de relieve la necesidad de abrir alguna vía de reflexión. Por ejemplo, si el objeto a juzgar es la capacidad "universitaria" -y no precisamente de dar mejores soluciones a lo siempre propuesto por la "corriente principal"-, ¿cabría proponer otros problemas más radicales, fuera o contra esa corriente hegemónica? O si el sistema de jurados es semejante al del resto de premios ¿quizá se podría tratar, no de crear un jurado exclusivamente universitario (copiando el recurso corporativo y corto de vista de hacer que el diseño sea juzgado solo por diseñadores), pero sí de elaborar criterios específicamente universita-

24. De hecho los jurados suelen manifestar una corriente estándar, de intencionalidad compleja y difusa, es decir, sin carácter específico. Es habitual recurrir a tópicos como la internacionalidad o la "iberoamistad", un tanto contaminados por la corriente principal. Sobre todo por su carácter mimético, con efectos publicitarios, interesados, expansionistas... que suelen encubrir la ausencia de una reflexión propia.

25. Splichal, S. "Eclipse of 'the Public'. From the Public to (transnational) Public Sphere. Conceptual Schifts in the Twentieth Century". En Gripsrud, J. \& Moe, H. (eds.) (2010). The Digital Public Sphere. Challenges for Media Policy.

26. Ver "La quiebra histórica..." (cit.). rios, lo que trasladaría la reflexión a un campo de juego aún poco definido en el diseño?

La composición de los Jurados actuales de los PFG parecen interpretar la especificidad por la vía de integrar todos los cuerpos concernidos (lo cual ya es una a novedad frente a los habituales jurados endogámicos, sólo de diseñadores). Pero incluso así resulta un tanto injustificable e impreciso su tópico "de reconocido prestigio" (¿qué tipo de prestigio: artesanal. estético, estratégico, productivo o reproductivo?), y también otros atributos poco definitorios de los supuestos premios universitarios ${ }^{27}$.

Instrumentos de evaluación. Queda un elemento clave para reducir bastantes de las imprecisiones o déficits identitarios apuntados a través de los elementos anteriores. Se ha percibido un gran esfuerzo, perseguido tras cada convocatoria, por conjugar los criterios de un Jurado numeroso y reducir el trabajo de racionalización estadística, para lograr la confluencia numérica ("científica") en las diversas categorías de cada convocatoria. Hace ya tiempo que la crítica moderna a la sociología y a otras ciencias humanas puso de manifiesto la prevención frente a la implicación del sujeto observador y la subjetivización de los datos "objetivos".

El repaso de la retícula preparada para facilitar el proceso deja ver aún déficits difíciles de evitar, pero demostrables y corregibles. A grandes rasgos, un filtrado aritmético al que se confía la objetividad de la resolución, no puede sustituir la discusión y los acuerdos previos de un Jurado. De nuevo aparece la práxis que conduce a la pertinencia de la realidad ${ }^{28}$.

El campo de la acción: la política. El breve repaso al peritexto más próximo podría extenderse a otros elementos importantes, como los tutores, las escuelas, su coordinación, etc., con lo que se apreciaría mejor el sentido orgánico del proyecto

27. El que los profesionales tiendan a aparecer como el grupo más compacto e indiferenciado (PFG 2017), parecería suponer que la única mejora posible sería de tipo ético-individual, y alcanzaría su tope con unos jurados rotativos, que permitiesen un goce igualitario de los minutos bajo los focos. Todo diseñador tendría el derecho y la oportunidad de ponerlo en su currículo, y de ese modo el círculo reproductivo del diseño sería perfecto y eterno...! Más allá de la broma y de la reducción al absurdo, un cambio en la concepción de la ética (de privada a pública: a moral) quizá moderaría la lógica anterior, que, en su extremo parecería conducir a la banalidad y la prescindibilidad de los premios y del diseño. Para algunos, al igual que el arte, su desaparición no se notaría: "es un complot": Baudrillard, J. (2006 ) El complot del arte. Ilusión y desilusión estéticas, 120.

28. Prieto, L. (1977). Pertinencia y Práctica. Ensayos de semiología. 
(moderno), frente al disperso, habitualmente explotado desde posiciones más individualistas $y$, paradójicamente, más unitarias (mainstream). El contexto total no sería ya más o menos próximo y particular, sino que coincidiría con un horizonte total, universal, sin duda más complejo, pero con más perspectiva. La identidad no es ya solo un proyecto narcisista ni estetizante, sino que se desarrolla en el campo exterior y público, y la pólis es el escenario en el que las entidades representan su trabajo. Es improbable que un sector sin instituciones ${ }^{29}$ (sin algún poder) pueda asumir responsabilidades y realizar este trabajo público sin verse reducido a una mini-historia, interna y de corto alcance.

\section{Repercusión del peri-texto en la evaluación}

Frente al panorama anterior parece relevante que los PFG, por su contenido, convocatoria y definición, sean la primera iniciativa, en su campo, para evaluar la calidad universitaria de los diseñadores. Sin embargo se pueden anotar tanto algunos problemas como algunas oportunidades, ambos derivados de la interpretación de cada uno de los factores señalados en el anterior epígrafe.

- El hecho de ser el primero parecería llevar implícito un propósito de continuidad. Ante la general carencia de series estadísticas fiables, esta iniciativa podría generar datos periódicos interesantes para el conocimiento no solo de la labor docente sino del estado del diseño a través de sus instituciones. $Y$ podía ser un observatorio fiable para la toma de decisiones políticas particulares.

- La composición del Jurado podría reflejar también criterios estables aunque revisables. Una variación continua, indiscriminada o multitudinaria de los miembros parecería instalarse sobre el sofisma de que la diversidad de miembros producirá de manera automática la verdad sobre la situación, sin antes definir qué atributos habría que juzgar en su permanencia o en su variación. De lo contrario se podría caer también en una trampa lógica que en realidad podría valorar cosas distintas en cada convocatoria.

- La consideración anterior podría evocar una peregrina y engañosa pureza de sangre, si, por ejemplo, se admitiese que los miembros de los jurados debieran ser variados, "pero siempre que fueran diseñadores". Es habitual topar-

29. En el sentido antes tratado: ver nota 10. Y también Douglas, M. (1996). Cómo piensan las instituciones (cit.). se con el aforismo endogámico de que quien sabe hacerlo lo hace y quien no, lo enseña, que se enuncia sin rubor. Bajo una apariencia funcional, sería la expresión de un "mundo del diseño"30 uniforme y feliz en su provincianismo intelectual.

- Los procesos de evaluación, y no solo el Jurado, podrían también reflejar todo el sistema en su coherencia y especificidad. En este sentido el Acta proporcionada para la evaluación resulta algo peculiar. Perceptualmente (el fuerte del diseño gráfico) aparece como una simplificación del trabajo, con dos únicas variables: Presentación y Contenido. También parece adecuada y aceptable la intención de cada subdivisión temática, pero cuando se propone traducir los supuestos indicadores a categorías y números (afortunadamente, no a "porcentajes con dos decimales" como expresión de "lo científico"), puede producirse un salto lógico hacia una "verdad" que desde el punto de vista metodológico ha sido ya muy discutida. Además, cada una de las variables se subdivide en subvariables, que a su vez se dividen en otros subindicadores, cada uno con varias categorías de evaluación.... Este "árbol lógico" llega a introducir una abultada cantidad de entradas a calificar y a reducir. Al final la complejidad es tal que puede darse no solo que haya solapamientos y redundancias, sino que resulte un verdadero examen al evaluador ${ }^{31}$.

- Tampoco parece muy defendible la reducida importancia dada en el conjunto a la metodología general, reflejada en una simple puntuación que en el total se nivelaría (por un efecto parecido al de la ley de los grandes datos) con otros apartados más formales o instrumentales. De nuevo habría que remitirse a una discusión o argumentación de esa metodología, concepto, por otro lado, no preciso ni previamente com-

30. Expresión utilizada dentro de la teoría institucional del arte (Dickie, Danto...), de la que es deudora la expresión "mundo del diseño" y también "circuito del diseño", utilizadas en estas líneas. Danto, A. C. (1964). "The Artworld», The Journal of Philosophy, 61. Dickie, G. (2005). El círculo del arte. Una teoría del arte. Ver también nota 7.

31. En un ambiente celebratorio y euforizante sería posible la paradoja de que esta hipertrofia "burocrática" llegase (por sinécdoque/contigüidad)) a magnificar la pequeñez de los proyectos, o a engrandecer al estamento "profesoral-judicial", justificando lo complejo de su actuación... Sin embargo hay que señalar que la organización nunca ha impuesto su sistema sino que lo ha ofrecido como ayuda. De todos modos, mas allá del problema técnico de la cuantificación, no hay que perder de vista que el principal tema de estas líneas es un cambio posible de modelo y de orientación, y no solo de los Premios, sino del diseño y de la sociedad como término de su actuación. 
partido, que denota la falta de una terminología universitaria común en el campo del diseño ${ }^{32}$.

- En otro sentido, el análisis de la bibliografía debería revelar tanto el marco teórico y la posición desde la que se habla, como el método específico o la metodología adoptados, pero se suele reducir a un trámite tópico y neutro, de contenido en su mayor parte artesanal, personal, tecnológico, o arbitrario y a veces exclusivamente con fuentes $h t t p: / /$.

- El Jurado podría ser un elemento clave para evidenciar de algún modo el tipo de premio, su ideario o "color", tal como las revistas universitarias o de calidad marcan su nivel o tendencia mediante su selección del consejo de redacción, del consejo consultivo, etc.). A semejanza suya podrían mantener una relativa permanencia, o una relación visible con el ideario (Junta Colegial, representantes de universidades, u otras fórmulas mixtas).

- La reflexión sobre todas estas características podrían hacer de este Premio un modelo repercutible en otros de distinto contenido y extensión. Esto sí podría producir una variedad de opciones sólidas, frente a la monotonía habitual, reforzada por la monotonía y mimetismo estatutario de asociaciones, fundaciones, centros, encuentros, festivales, galas, y otros pseudoacontecimientos, que reflejan y reproducen una sociedad de pensamiento único y sin fisuras. Que la universidad deba ser un reflejo de la sociedad es otro sofisma tan discutible como impune.

- Se puede añadir también la conveniencia de unas directrices para el Jurado, que reforzarían y unificarían el "ideario" específico de los Pre-

32. Problema señalado de manera muy reiterada por Margolin, V. et al. (2009). Las Rutas del Diseño. En el fondo se evidencia la vacilación del diseño entre la valoración de las ciencias humanas y de las "exactas". Hans-Georg Gadamer (1988) en su Verdad y método. Fundamentos de una hermenéutica filosófica. Sígueme. Salamanca, podría servir para situar el problema general: "¿Qué clase de conocimiento es éste que comprende que algo sea como es porque comprende que así ha llegado a ser?" ( $p$. 33). En este caso, por ejemplo, desde una perspectiva no instrumental es difícil apreciar la oportunidad de la expresión "adaptación al usuario final", que implica ya la aceptación de un término "marcado". De igual modo el equilibrio entre "creatividad y pertinencia", difícil de responder sin previa aclaración y consenso de ambos términos (sobre todo el de "creatividad", admitido hoy, sin crítica, como unívoco). Etc. Esta es la razón por la que se ha insistido en un acuerdo previo a la labor del Jurado, sobre las características de un trabajo universitario, sobre el sistema de valoración cuantitativa, etc. Por esta razón el autor se excusó por utilizar otro procedimiento de calificación, en forma de ponderación personal, que ofreció como propuesta de discusión tras la primera convocatoria de los PFG, y que en parte se detalla en estas líneas. mios. De este modo un Jurado disperso podría reconducirse hacia una evaluación no genérica, sino específica e identificadora del emisor.

- De algún modo la justificación y argumentación explícita de las evaluaciones y resultados podrían ser no solo un derecho de los presentados, sino un elemento pedagógico que reforzaría los enunciados programáticos.

Insistiendo en el carácter inaugural de estos Premios, las anteriores notas se transforman en sugerencias, en realidad tan poco originales como poco practicadas e institucionalizadas.

¿Qué mide el PFG?

Si la denominación de los Premios marca la especificidad universitaria, tanto en su primera versión directa (PFG), como en la segunda, más oblicua (Gaudeamus) ${ }^{33}$, debería quedar claro que de lo que se trata es de mostrar (antes que medir) ese carácter universitario. Los demás atributos serían secundarios -incluso el preferido y habitual de mostrar habilidades para el mercado de trabajo-, y tal vez más cómodos para el modelo actual de sociedad hiperestetizada, como es la del último capitalismo ${ }^{34}$.

Tras la descripción de la composición del Jurado y de los procesos de evaluación, se podría suponer la uniformidad y previsibilidad de los resultados. Sin embargo la deseable pluralidad y diversidad se generaría, no como expresión individual y privada sino colectiva y pública. Se advertiría como diversidad y riqueza institucional, cuando cada miembro coincidiese libremente en la categoría y el tipo de representatividad supuestamente atribuida a la entidad organizadora, semejante a otras de similar productividad social, y por lo mismo, diferente de las que representasen identidades sociales re-productivas, hoy mayoría ${ }^{35}$.

33. Remitir a rutinas de la Identidad Corporativa (en este caso las del flamante naming) sería sumergirse en un nivel instrumental por el que deliberadamente no se ha querido pasar sino de puntillas. Aun así, y acorde con el discurso general mantenido, quizás se pudiera tolerar la impertinencia de una mínima llamada a revisar el nombre de los PFG, antes de lanzar su cuarta edición. 34. Jameson, F. (2001): El postmodernismo o la lógica cultural del neocapitalismo ("late capitalism", en el título original).

35. Tal como ya se ha descrito, este planteamiento parece entrar en contradicción con los sistemas evaluativos previstos por la organización de los PFG, a pesar de su comprensible intento de reducir la complejidad. Por esta razón, en una alternativa de evaluación habría que dar cuenta de la divergencia de criterios y de la dificultad de identificarse con la valoración numérica sugerida. No se trata de displicencia. Por el contrario, se toma tan en serio la el empeño de dar una interfaz conveniente a los Premios que una enmienda a la totalidad puede resultar más productiva que la incierta sumisión a las normas. 


\section{Crítica del procedimiento operativo}

Antes de pasar a los elementos operativos y funcionales conviene aclarar y sintetizar, de la manera más urgente y breve posible, lo que a lo largo de las líneas anteriores de ha ido desgranando de manera dispersa y quizá insuficientemente aclarada.

No se trata de invalidar ni despreciar el esfuerzo y trabajo anteriores, sino de poner de relieve la confrontación de dos universos u horizontes opuestos, y de poner el esfuerzo y la energía detrás de la elección libre, discutida y razonada, de uno de ellos. De este modo también se concedería a los jurados la oportunidad de adherirse o no a una "empresa" con un programa manifiesto. Para toda la sociedad, pero de manera especial para el campo del diseño, donde parece darse una inconsciencia en cierto modo patológica ( $y$ endémica), que hace que esta reflexión se encuentre tan ausente como minoritariamente requerida. No se habla de una elección entre elementos instrumentales, intercambiables o alternativos, sino entre elementos configuradores del sentido de la marcha. En este sentido, el concepto bipolar más comprehensivo y más aludido en este escrito —el de modernidad/postmodernidad — deja suficientemente claro los aspectos divergentes entre los que es necesaria una discusión y una opción de base ${ }^{36}$, que parece haberse omitido en el horizonte de la sociedad, y por lo tanto (o muy especialmente) en el llamado diseño ${ }^{37}$. Se trata de evidenciar un problema sistémico y dialéctico, que se puede reducir al citado como postmodernidad "filosófica" vs. postmodernidad "vulgar".

Con estas premisas tal vez puedan quedar mejor aclaradas tanto las dificultades encontradas frente a los instrumentos de valoración, como el sentido de las variables propuestas como atributos del trabajo universitario.

Como alternativa a algunos supuestos déficits encontrados en la identidad de los PFG, y como se supone que debe ocurrir en una crítica ${ }^{38}$, se expone a continuación una posible propuesta de reconversión, tanto en la forma de la expresión como en la del contenido ${ }^{39}$. Se propone como reflexión

36. "Discutir palabras / discutir posturas. Sobre 'Arte \& Publicidad. La estrategia de la sustitución'. Respuesta a Inmaculada Murcia". Estudios Filosóficos n. ${ }^{\circ} 52$.

37. Ver aclaración del "llamado diseño" en: "La quiebra histórica..." (cit.).

38. No "constructiva", o paternalista: como muchos saben, crítica significa juicio, sin más adjetivos.

39. Como se sabe, estos términos se toman de Hjelmslev, no por pedantería ni con ánimo profesoral, sino solo para insistir en que, por un lado, se trata de las dos caras de un mismo signo, en este caso los PFG, donde la habitual prevalencia de uno de y como sugerencia, con la ventaja de que se ha probado ya con suficiente eficacia en las tres convocatorias habidas hasta este momento. Además, el hecho de haber localizado de manera empírica unas variables fundamentales como atributos del trabajo universitario, manifiesta la no vinculación a ningún prejuicio en forma de esquema previo, escuela, o ideología. Pero confirma la oposición —argumentada y expresa—, a la postmodernidad como "la lógica cultural del capitalismo tardío": una sociedad neo-colonial, manifestada en una cómoda corriente principal y que casi ha desactivado las capacidades reales de reacción.

\section{Variables principales (universitarias) ${ }^{40}$}

Se ha mantenido la metodología estadística, que toma en cuenta la proporción numérica de los trabajos en cada una de las variables seleccionadas. Algunas perspectivas interesantes, como la reflexión filosófica, histórica, lingüística, terminológica o semejantes, han aparecido solo de manera testimonial, como metodologías extrañas al discurso condicionado por el marco de valoración ya comentado, que favorece una perspectiva concreta de reflexión.

La mirada sobre los materiales, conceptualmente previa al análisis de los trabajos, se ha reafirmado a partir de características percibidas en los discursos y textos particulares. En este sentido, las posibles dimensiones universitarias se han seleccionado a partir del texto mismo de los trabajos presentados, es decir, tienen carácter empíri$\mathrm{co}$, sin prejuicio ni trabajo especulativo previo. Según estos supuestos, han aparecido con claridad unas características muy llamativas, que se han llevado hacia un nivel de abstracción productivo más allá de los hechos mismos. Cada una de las notas se definen por tanto, no de manera esencialista, sino por oposición a sus contrarios concretos, manifiestos también a lo largo de cada uno de los trabajos. Frente a algunas otras posibilidades de elección se ha optado por reducir la dispersión

los elementos (generalmente el primero, la construcción estética), desfigura e ideologiza el signo completo, torciendo también la lógica del discurso; y que, por otro lado, se pretende apoyar lo expuesto acerca de las variables y los criterios de calificación, entre los cuales, como se verá, se ha omitido precisamente la estética. 40. Ya se ha advertido que los datos y la metodología de este esbozo de análisis corresponden en general a notas tomadas a partir de los trabajos de la primera convocatoria de los PFG. A pesar de su carácter de provisionalidad, se ha confirmado consistencia en las dos siguientes convocatorias. El título primero del artículo indicaba ya las características que permanecen en el campo temporal más amplio de las tres convocatorias realizadas: "Hipertrofia del significante (estética)/Transubstanciación del significado (trucaje lógico)/Atrofia del sentido (corriente principal)". 
a tres variables básicas y dos complementarias. Las básicas persiguen el objetivo principal: juzgar el carácter universitario como atributo principal de los aspirantes a los Premios Fin de Grado. Las secundarias intentan recoger caracteres más comunes y propios del oficio.

Las variables básicas, o principales, remiten

- a la temática elegida bajo el concepto de realismo $(R)$,

- al discurso general mantenido sobre esa temática como coherencia lógica ( $L$ ),

- y al resultado de todo el proceso como socialmente productivo (S).

Realismo. La primera percepción tras la lectura de los trabajos es la carencia de realismo, algo esperable hasta cierto punto si se considera la inexperiencia biográfica de los alumnos, pero menos admisible si se considera la responsabilidad tutoral y docente.

Puede que el desconocimiento o la omisión de la realidad lleve a crear ficciones como realidad. $Y$ puede que la causa inmediata sea que los estudiantes están previamente abducidos por el sistema publicitario, reproduciendo la pose exhibicionista del inglés, con "claims", titulares festivos, metalingüísticos, infantiles...: creen en ese sistema como en la verdad, por lo que puede que no perciban ninguna contradicción lógica entre su creencia y sus productos. - Para creer hay que tener fe..., y esta máxima de ascendiente solipsista sugiere también ciertas conexiones entre diseño y religión.

Los enunciados de los trabajos revisados son en gran parte miméticos de los titulares mediáticos (publicidad, cine, cómics, columnismo, glamour...), con prevalencia de la función conativa o persuasiva. Se supone que un trabajo universitario debería consistir en el abordaje de un problema real, no en una prueba literaria de ficción autocomplaciente ni de implicación simplemente individual. El indicio detectado en los titulares se suele mantener, salvo excepciones, en el desarrollo del discurso ${ }^{41}$.

41. Como ejemplo de otros posibles planteamientos puede verse una relación de propuestas de trabajos de un centro universitario no homologado con el Grado de Diseño.

1. - uso cotidiano: ORA, señales tráfico, averías, parkings, abrefáciles, bisagras...

- interfaz de máquinas expendedoras (transportes, surtidores, parking...)

- manuales de uso, prospectos médicos...

- formularios de utilidad pública: hacienda, bancos, servicios...

- homologación de códigos de productos (leche, interdentales...)

packs y reciclaje: en origen vs. en usuario

- gráfica aplicada: máquinas, objetos, envases...
Gráfico 1. Ejes de las variables

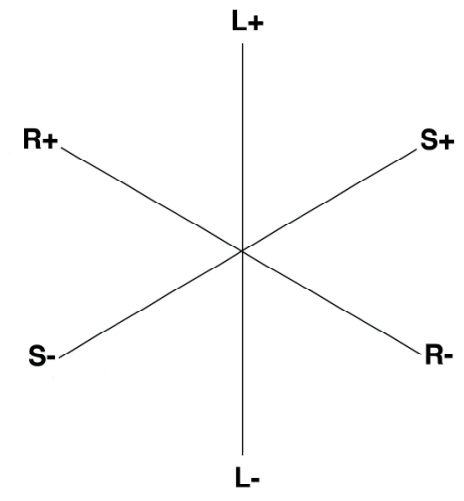

La cuantificación de las variables dominantes encontradas se va a expresar como variables continuas en un eje bipolar: Realismo $( \pm R)$, Lógica $( \pm \mathrm{L})$ y Sociedad $( \pm \mathrm{S})$.

Los valores de cada eje se resolverían de manera suficiente con tres niveles

REALIDAD-LÓGICA-SOCIEDAD positivos.

\begin{tabular}{c|c|c|c}
\hline \multicolumn{4}{l}{ Cuadro 1. Variables principales } \\
\hline Espacio & Variable & Sentido & Descriptor (PFG) \\
\hline problema & realismo & necesidad & mitologías individuales \\
\hline discurso & lógica & coherencia & mixtificación/legitimación \\
\hline acción & sociedad & producción & instrumentalismo
\end{tabular}

El sentido equivale aquí a una formulación positiva de lo detectado en los PFG como notas sobresalientes negativas.

Parece que en todos los centros se han prescrito una serie de requisitos metodológicos, en los que se indica que cada trabajo debe presentar un objetivo, un problema concreto detectado en el mundo y al que se pretende dar una solución, donde cabe definir su importancia, su oportunidad, su utilidad, enfoque, posibilidades, etc. Dentro de esas precisiones los trabajos podrían haber sido muy variados. Sin embargo al observar los Proyectos se han encontrado otro tipo de uniformidades llamativas que se han entendido como ajenas al eje del realismo. Sobre un eje rea-

2. - publicidad estatal: diferenciada o mimética de la comercial - uniformidad y diversidad asociativa: grupo de presión vs. corporativismo

- medida del \% del diseño en el PIB

sistema de estadísticas sobre diseño: periodicidad y uniformidad

- las ESD: uniformidad vs. diversificación

- modelos de selección para el Premio Nal. Diseño

- estructura y contenido de portales y blogs de diseño: Foro Alfa, Issuu, TED...

- exposiciones, prensa, producción editorial, premios..., de diseño en España

- formatos, contenidos y financiación de museos de diseño... 
lidad-irrealidad esta situación parece negativa en relación con la misión analítica universitaria, en general, si se exceptúa (y sólo de cierta manera), las disciplinas de creación artística plástica. literaria, musical...). Sin embargo los términos realidad y realismo se han entendido solo de manera operativa y coyuntural (no se ha pretendido entrar en discursos históricos, especulativos, abstractos, etc.), solo deducidos de una práxis definida por datos concretos. Se han encontrado elementos interpretados como opuestos al realismo, y que adoptan formas desde la ficción, la especulación narcisista, el solipsismo endogámico, la realidad virtual, el irrealismo zombi ${ }^{42}$, o ciertas formas delirantes. En algunos casos pudieran rozar cierta experimentación artística, no confundible con la función estética de la comunicación, pero, hasta el momento, no ha sido lo preceptivo ni lo canónico en los programas del diseño convencional.

Coherencia lógica. Las tres variables encontradas (en sus formas carenciales), forman además un sistema y un discurso, también universitarios, por lo que la coherencia o consistencia (lógica) se entiende entre el problema inicial y la solución propuesta. No se descubre nada nuevo si se señala que la no aceptación de un trabajo "no realista", en el sentido señalado, debería haber cortado el paso al análisis del siguiente requisito (entendiendo que no es claramente separable por una línea de puntos, ya que la lógica sistémica no es sucesiva sino dialéctica). Tampoco es nuevo, pero se puede dejar descrito, que los materiales para analizar la coherencia abarcan la documentación aportada tanto para definir y describir el problema como para justificar su importancia y su elección. Este marco general debería seguir los lógicos pasos de fijar límites, merecer la aprobación de los argumentos -incluso los de autoridad, como la Bibliografía), establecer procedimientos, estrategias, recursos, etc., de modo que la realización final mereciese la aprobación y satisfacción ante el resultado o las posibles opciones expuestas. Hay que anotar también que la coherencia se establece

42. Uklric Beck ya usaba hace tiempo este término en el mismo sentido, citado por Bauman, Z. (2002) Modernidad líquida, p. 12. En una breve reseña como es el presente escrito, quedan muchos campos semánticos por definir (ver nota 29: Margolin) y muchos cabos por atar. Valga como disculpa el que es solo una muestra del trabajo por hacer, pero cualquier reacción acerca de sus insuficiencias y su provisionalidad se consideraría ya un logro, y sería bienvenida. A pesar de todo, solo con un repaso directo de los titulares de los trabajos presentados se podría tener una idea suficiente y sustituir otras explicaciones prolijas y enredosas. como una lógica ${ }^{43}$, que da corrección, convicción y certeza (no verdad) al pensamiento desarrollado entre los términos inicial y final. Y este sería el momento de comenzar a realizar el trabajo o proyecto propuesto; lo que querría indicar que lo anterior sería propiamente una labor principal y conjunta con la tutoría. Y esta parece que sería también la perspectiva universitaria, propia de un pensamiento "científico" frente al "vulgar".

Esa coherencia interna se echa en falta en general en gran parte de los trabajos. Lo cual podría indicar un seguimiento tutoral discutible, una idea excesivamente respetuosa de la función autoral y tutoral, al permitir una "creatividad" explosiva, o la creencia en que es precisamente esa creatividad lo que se piensa que hay que fomentar ${ }^{44}$.

Una lógica coherente asegura un tránsito probable entre la percepción de la realidad y su trabajo productivo sobre ella. La coherencia discursiva recorre los tres ejes indicados de manera sistemática: las teorías, las metodologías y las propuestas de actuación. Pretende evitar las posibles fugas lógicas y detecta la posible contaminación con intereses particulares.

Las formas dominantes de la quiebra lógica tienen ascendientes en lógicas de la tautología, identificables en la mixtificación, en el sofisma (el entimema publicitario como preferido), o el desvío argumental interesado (el "efecto Pisuerga"), todo lo cual plantea un problema serio desde el punto de vista de la forma de pensamiento exigible en una titulación universitaria.

El desfallecimiento argumental puede tener también origen en una potente pulsión inicial que urge y desvía una posible razón sustantiva hacia una razón -y sobre todo acción-instrumental. Esta falta de honestidad intelectual sería también un grave problema para un estatuto universitario libre, con previsibles graves consecuencias en la sociedad real. De hecho es patente el paulatino desvío desde

43. Al igual que se ha tratado también como una "lógica" la posición del "postmodernismo vulgar" (ver nota: Jameson). El problema de la identidad del sujeto, o el de la verdad, constituyó el tema central de la revisión moderna de sus propios supuestos, y dio lugar a la llamada postmodernidad filosófica ya citada. Un debate sobre el paso de la verdad a la certeza como base de la condición postmoderna puede encontrarse en una amplia bibliografía, en concreto en los intercambios entre Quine-DavidsonRorty..., o en el curioso libro de Hofstadter, D. R. (1982). Gödel, Escher, Bach: un eterno y grácil bucle. Tusquets. Barcelona. 44. En cualquiera de los casos el Jurado no tiene información de todo este panorama que se pretende que sea el objeto "específico" de su juicio, ante lo que quizá se debiera acordar posturas previas que diesen solidez institucional a todo el proceso. Esta fue la intención de un debate a partir de los cometarios solicitados al Jurado tras los primeros PFG. Ver nota 1. 
las grandes teorías (que ocupan al menos un tercio de la argumentación de buena parte de los trabajos, en los que en su comienzo aparece cierta pluralidad) hacia la simple y homogénea práctica reducida a un "saber hacer" interesado. Parece surgir una querencia hacia un saber-hacer instrumental, rastreable con frecuencia como centro de interés docente. Desde el inicial "pegar el grito", a lo que finalmente se ofrece, o que ya desde el principio se había íntimamente decidido ("yo lo que quería era hacer un logotipo", p. e.), se encuentran muchas muestras del horaciano "parto de los montes" 45.

Productividad "social". Finalmente, el resultado es valorado como productivo o no productivo para la comunidad, es decir para el espacio público o sociedad. No hace falta insistir en que las trampas del lenguaje pueden decir lo mismo haciendo lo contrario, o que pueden sonar diferente con la misma letra, pero el valor del término producción se aclara mejor al oponerlo, en un eje semántico, a re-producción. $Y$ ya que es propio de la corriente principal imponer un uso dominante del lenguaje, sería también función de la Universidad descubrir y confrontar las falacias del lenguaje y las ideologías ocultas, que generalmente ocupan su lugar como descriptores de la postmodernidad vulgar.

Aunque pueda resultar ya un pleonasmo explicativo, se puede insistir en el sentido de lo productivo-social como la capacidad de cambio hacia mejoras comunes, aunque este objetivo requiere también una definición y acuerdo acerca de lo que se entiende por mejora y por común. Por lo general los contenidos (objetos) y vías (procesos) de tipo instrumental dejan intactas las estructuras existentes, por lo que se pueden calificar de conservadoras, cooperativas con el statu quo, re-productivas. Las opciones de tipo productivo promoverían en cambio la participación regenerativa y progresiva (no confundir con "lo nuevo" ni con "lo creativo"). Entendida de este modo, esta tercera variable, se compenetra de forma sistémica con las otras dos elegidas, y sería a la vez un corrector universitario del irrealismo y de la lógica del interés particular.

Es percibible el tono de "deber ser" de este discurso, que de manera convencional es aceptado como un fin genérico, y que, también de manera convencional, se vincula más al pensamiento llamado humanístico que al politécnico. En cualquier

45. "Parturient montes/nascetur ridiculus mus". HoRAcio, Q. Ars Poetica, 128.

\begin{tabular}{c|c|c|c}
\hline \multicolumn{4}{l}{ Cuadro 2. Variables secundarias } \\
\hline Espacio & Variable & Sentido & Descriptor (PFG) \\
\hline comunicación & claridad & recepción & mitologías individuales? \\
\hline objeto & complejidad & funcionalidad & mixtificación/legitimación? \\
\hline
\end{tabular}

caso, y pese a toda convención "moderna", se puede afirmar que a toda acción y a toda lógica precede una elección, una opción. Y que en un desideratum (ideal), tanto el realismo de un problema como su solución tienden a ser calificados como beneficiosos, no para el individuo aislado sino para su interfaz público, y, en consecuencia, político. En síntesis: la productividad se entiende como una conveniencia social, un mandato institucional, cuyo espacio de coincidencia y de producción no es el de la subjetividad y el solipsismo, sino un espacio socio-político (de la pólis), prácticamente ausente — salvo indicios fragmentarios- en el discurso de los PFG.

Además, en general los trabajos se sitúan de manera disgregada e individualista (no hay trabajos de equipo), fomentando la "obra" personal mediante el trabajo autónomo, en consonancia con un mercado en el que pretenden exhibir en forma competitiva sus habilidades y destrezas, solicitadas previamente por ese mismo mercado. Esta condición chocaría con el mandato de la productividad social, de la función de la universidad..., e incluso de la "creatividad". En resumen: sólo la previa aceptación del lenguaje de la poderosa corriente principal puede expresarse con las mismas palabras con las que bastantes universitarios han presentado su Proyecto.

\section{Variables secundarias (profesionales)}

Se ha privilegiado las variables universitarias como principales, en parte como discriminación positiva, ante el paso desapercibido de este atributo identitario en los PFG. Pero no indica desprecio a otros atributos de carácter más bien funcional, en los que se ejerce el desarrollo concreto de los primeros, y en los que también se demuestran ciertas competencias profesionales correspondientes al nivel del Grado. Las variables seleccionadas - por el mismo procedimiento empírico que las principales-, y los descriptores de sus ejes han sido la comunicación (clara vs. compleja, prolija), y el tipo de objeto (compuesto vs. simple, único).

La comunicación no es una variable específica de carácter universitario, pero es un factor clave en el sector Gráfico, que ostenta el Col.legi en su denominación y definición institucional. Al ca- 


\begin{tabular}{l|c|c|c}
\hline \multicolumn{4}{l}{ Tabla 5. Variables principales (conceptuales) } \\
\hline PFG & 2017 & 2018 & 2019 \\
\hline realismo & 30 & - & 27 \\
\hline coherencia & 32 & - & 24 \\
\hline productividad social & 15 & - & 20 \\
\hline Total trabajos & $\mathbf{6 1}$ & $\mathbf{5 4}$ & $\mathbf{4 2}$ \\
\hline
\end{tabular}

lificarlo como variable secundaria no deja de ser considerada como universitaria, y por tanto tendría que aportar la correspondiente identidad a los PFG. Baste con anotar que su mayor problema no sería la incompetencia en el oficio, sino el peligro de su inmersión en jaula de hierro de la estética (de la que se hablará a continuación), con su ya citada invasión de "mitologías individuales" como descriptor fáctico. Además de tener que encontrar y mostrar competencias que, de nuevo, denoten otro nivel más analítico o estratégico, y más centrado en la recepción (la responsabilidad de la configuración del imaginario público, la intermediación entre las estructuras de la industria de la comunicación y las de dominación, etc.). En suma, más iniciados en el terreno de lo público y de lo político (siempre la pólis), más propio de un grado "universitario".

La selección de otra variable secundaria, la tipología del objeto sobre el que se ejerce la demostración, se puede entender del mismo modo que la anterior. Baste también con dar alguna llamada de atención sobre los peligros de la apropiación "postmoderna" del lenguaje en cuanto a su entendimiento de la funcionalidad ${ }^{46}$. Por otra parte, más allá de la materialidad del objeto —es obvio que no es lo mismo una taza impresa, un cartel, o una campaña, que una identidad completa - cabe indagar en la nueva inmaterialidad y sus problemas. Puede ser un campo menos obvio y menos en competencia con otros muchos premios que coinciden en el mismo terreno (y que probablemente también hablan de "investigación"). El aspecto objetual y material del DG abriría también otro espacio de discusión.

Las variables secundarias en unos aspectos siguen siendo continuas, polares y contenidas en su cuantificación, ya que comparten una lógica estadística semejante con las variable principa-

46. El diseño en sí es lo más funcional para el capital! BAUDRILLARD, J. (1999): El sistema de los objetos. les. También comparten los descriptores perceptuales (de primer impacto). En principio se puede pensar aquí en un efecto lógico de contaminación estructural entre la forma del contenido y la inseparable forma de la expresión. Pero —más importante- su inmediata relación con la estética (aísthesis $\approx$ percepción, de la que se hablará de inmediato), en su paso al nivel objetual, legitimado de manera simbólica en gran parte por la forma (como se indicó en el epígrafe 3.1.), hacen más significativa aún la atribución de estos descriptores a las variables secundarias.

Además, los conjuntos intersecantes de las dos variables pueden formar un campo semántico común en el que prolifera la metáfora... espacio tanto de la poética como del isomorfismo o de la posible mixtificación ${ }^{47}$, a lo que habrá que prestar atención ante las lógicas habituales del postmodernismo vulgar.

\section{Resultados del análisis}

Variables principales

Tal como se han explicado las variables, los resultados estadísticos han sido los que se indican en la tabla 5: que más de la mitad de los trabajos fallen en realismo o en consistencia conceptual es una cifra bastante alarmante. Mayor aún es el déficit en proyección social productiva, es decir, en generación de cambios positivos sobre la situación actual (¿con indicios de mayor equilibrio en la tercera convocatoria?).

Del análisis de las tres variables principales se desprende un panorama bastante desolador, ya que en un resumen somero de los resultados estadísticos aparece como sobresaliente:

- que la temática aparece en buena parte como extraña a un entorno universitario convencional;

- que buena parte del discurso sobre la propuesta temática, no parece mantener ni sostener una consistencia lógica ni con el objeto final propuesto ni con los valores esperados ${ }^{48}$;

- que la amplia promesa inicial desemboca en muchos casos en soluciones instrumentales, reflejo de la corriente principal o de los programas de habilidades orientados al mercado actual: ambos componentes de la tópica "creatividad" re-productiva, no genuinamente productiva.

47. LAKOFF. G. - Johnson, M. (1986): Metáforas de la vida cotidiana. 48. Entre el principio y el fin del trabajo parece darse un trucaje - a veces enturbiado por lo prolijo del desarrollo documental-, que escamotea y quiebra la línea argumental iniciada. Quizá ocurra porque el individuo se adecua a su propio nivel de comprensión del tema elegido, por cansancio mental, o por anticipación de su deseo encubierto, algo resoluble desde una orientación tutoral. 


\section{Variables secundarias}

En las variables secundarias se destaca que en la elección del objeto del trabajo se da un mayor (y progresivo) descuido y desatención que en su comunicación. Podría interpretarse como indicio de una creciente competencia comunicativa, pero también como una mayor atención a la transmisión estética que al producto mismo, concordante con el papel legitimador del DG y el auge de la apariencia como legitimadora de los objetos del nuevo "empresariado estético".

Por último, el cuadro que ha guiado esta narración sobre las variables seleccionadas, se podría resumir en improvisados "titulares" el choque producido al leer los Proyectos desde una perspectiva deseada:

- se buscaba un realismo basado en necesidades comunes y se han encontrado mitologías individuales,

- donde se esperaba una lógica comprensible y convincente se ha encontrado mixtificación y legitimación de lo irreal,

- y donde se esperaba encontrar fórmulas o sugerencias creativas para necesidades reales y comunes no cubiertas, se han visto re-producciones "novedosas" (estéticas) que perpetúan, con mucha competencia, el camino ya trazado.

Ante todo, estas apreciaciones son en general frustrantes, desde el punto de vista de lo esperado y descrito en estas páginas. Pero, por si de este modo se pudiera aliviar esa impresión:

- se trata de elementos sobresalientes en el conjunto, no participados por todos los concursantes

- proceden de una perspectiva propuesta a discusión, y solo por un miembro del Jurado

- según otras perspectivas, los resultados parecen haber sido bastante satisfactorios.

Sin embargo, aunque lo positivo y complaciente halaga y tranquiliza, resulta inevitable y obligado emitir ciertos juicios, que no son en sí negativos sino emitidos desde otra perspectiva, sin duda positiva.

Estas líneas no pretenden sino mostrar algunas notas casi evidentes, aunque con muchas lagunas, que amplían razonamientos y posiciones expresadas con anterioridad en otros foros ${ }^{49}$. Pero no se trata de un juicio personal sino de la

49. Ver nota 5.

\begin{tabular}{l|c|c|c}
\hline \multicolumn{5}{l}{ Tabla 6. Variables secundarias (profesionales) } \\
\hline PFG & 2017 & 2018 & 2019 \\
\hline objeto & 27 & 8 & 7 \\
\hline comunicación & 29 & 43 & 36 \\
\hline Total trabajos & $\mathbf{6 1}$ & $\mathbf{5 4}$ & $\mathbf{4 2}$ \\
\hline
\end{tabular}

detección de discordancias cognitivas en todo este proceso, que han desencadenado un cierto malestar en la cultura del diseño $0^{50}$, y que estos Premios han servido como oportunidad de revisar o de reformular.

\section{¿Y la estética?}

Puede llamar la atención la no atención a una de las variables más atendidas por lo general, la estética, definitoria de una concepción de diseño en el que suele ser considerada como central, cuando no única. Por una parte esta centralidad puede considerarse como ideológica, pues arraiga en una idea salvadora y taumatúrgica de tipo individualista. De hecho es un instrumento legitimatorio que manifiesta el gusto actual de cierta elite urbana. Su representación histórica más conocida es el socialismo utópico y schilleriano del "primer Morris", mientras se deja de lado el llamado "segundo Morris", consecuente en cierto modo con el llamado socialismo marxiano.

Por otro lado, tras la revisión de los trabajos el evaluador constataba una excelencia estética singular en todos los trabajos ${ }^{51}$, lo que vendría a confirmar la primera razón de exclusión de esta variable: al reconocer a todos un mérito en grado semejante dejaba de tener valor discriminatorio. Pero por lo mismo aumentaba su significatividad, por su efecto de oclusión o desatención a las otras variables seleccionadas, cuya poca presencia ha merecido un juicio bastante más desalentador de lo esperado.

De este modo la discriminación de la estética se puede entender como positiva y militante. Sobre todo porque define un sistema que replica y proyecta la provincia del diseño. No es difícil aceptar que la referencia y el destino de la

50. Freud, S. (2013): El malestar en la cultura.

51. Excepto en tres de ellos, en los cuales la no excelencia no parece provenir de una actitud militante (que también ha aparecido de manera muy restringida), sino de insuficiencia, por lo que estas excepciones pueden considerarse casuales o anecdóticas. 
acción del diseño es el Primer Mundo (que hoy es ya todo el mundo, globalizado bajo un único modelo ideal), del que una de las características es la de ser una sociedad saciada, cuya ocupación fundamental es el ocio turístico, el "ludismo coercitivo" 52 , y cuya facultad más explotada-sometida es la creatividad. Ya de hecho la profesión más solicitada y entre-tenida sería el diseño, a quien se encomienda la función de entre-tener al resto de la sociedad.

La estética representada en los trabajos es fundamentalmente individualista, sentimental y ahistórica, como corresponde a su inmersión en una especie de "sopa primordial" que es el postmodernismo definido como "lógica cultural del último capitalismo ". Es una estética intransitiva, reducida al instante presente. $Y$ socialmente improductiva: por más que se pretenda entenderla como erudición de las formas o como democratización del gusto, se trata sólo de eclecticismo formal, de un panóptico estilístico ideologizado ${ }^{53}$.

\section{Conclusión}

A la vista de estos datos generales y tras los anteriores supuestos asoma una posible interpretación genética y de más calado.

- Por un lado, como ya se ha apuntado, la presión demográfica: existe una gran masa juvenil a la que el sistema postmoderno proporciona un sentido para su vida en una etapa de narcisismo forzoso y de grandes dificultades para enfrentarse a la cruda realidad.

- Por otro lado el régimen ficcional actual, que se centra en la satisfacción de necesidades periféricas ${ }^{54}$, cuyo modelo es el ocio turístico. Todo ello parece haber creado una epistéme social que instala una estetización de la realidad, adecuada a un sistema que dedica atención preferente a unos estratos saciados frente a otros de carencia. Por lo general esta operación tiene éxito en algunos países mediante la autosatisfacción narcisista y autoexpresiva de diseñadores y otros mediadores.

52. Bégout, B. (2007). Zerópolis, 49

53. "Stylization (aestheticization) of consumption": Lury, C. (1997) Consumer culture. Cambridge, Polity Press, 52. Esta secuencia de afirmaciones puede parecer dura, doctrinaria o subjetiva, pero en este caso (y quizá en algún otro) se explica por la necesidad de poner límite a este artículo. Y ya se ha señalado que algunas premisas, hipótesis y supuestos manejados han sido objeto de algún otro texto reciente (nota 5). Términos prestados y similares pueden encontrarse en autores como Jameson, Heller, Elias-Gill-Sharff, Lipovetsky (citados), y en Foster (2004), Zizek (2003)..

54. Heller, Á. (1996). Una revisión de la teoría de las necesidades.
En el mismo sentido, la histerización del lujo ${ }^{55}$ ha encontrado en el diseño su herramienta más funcional, haciendo del diseño el mayor instrumento de un lujo patético. Y todo ello mediante el artilugio mixtificador de la creatividad, instalado ya incluso en el lenguaje habitual de las grandes instituciones (ver nota 20).

Aun suponiendo que este panorama pareciese no solo duro sino excesivo o apocalíptico, poco de él se traduce en los textos y discursos analizados que, por el contrario y por lo general, definen por lo general un horizonte de mundo seguro y feliz, en el que no existe la menor disfuncionalidad estructural sino solo pequeñas disfuncionalidades operativas que el diseño viene a remediar. Se legitima así el statu quo dando forma aceptable a lo siniestro.

Frente a este escenario resulta también sospechoso, si no grave, el que los estudios de diseño hayan accedido a un "grado universitario" sin mediar la suficiente crítica desde el estrato aspiracional. Se cierra así el círculo férreo (la jaula racional de Weber) que ciega y obtura el progreso y la realidad misma. Por lo que puede deducirse de los trabajos analizados, los estudios "universitarios" de diseño parecen haber adoptado los supuestos y premisas de una especie de FP de élite, para unas necesidades previamente definidas y amaestradas, que, cerrando el discurso, son admitidas tautológica y crédulamente por los nuevos diseñadores, que pasarían a ser los mayores propagandistas o "intelectuales orgánicos" del sistema. Parece crearse así un nuevo estrato profesional, híbrido y contradictorio: un neoartesanado-liberal, o un tecnoartesanato. En este sentido ya se habla de un deskillment progresivo, que de forma desapercibida lleva hacia una "retroprofesión", desmitiendo, o al menos contrariando, el supuesto camino progresivo definido como "de oficio a profesión", ya citado ${ }^{56}$.

Todos estos movimientos tectónicos desapercibidos deberían al menos aflorar y detectarse en unos trabajos de supuesto nivel universitario. Lo peor de todo pudiera ser que no tuvieran ya otro foro o lugar de afloramiento y de debate.

Esta situación sistémica puede ser la razón de que, al sentir fuera de alcance el análisis y la crí-

55. González Solas, J. (2011). "Lujo tópico y distópico: Un marco para el diseño y la publicidad". Pensar la Publicidad 2011, vol. 5, no 1, 99-120.

56. Vélez, P. - Calvera A. (2014). De oficio a profesión (cit.). Ver también (muy recomendable) la incidencia de esta situación en el retroceso de derechos laborales conseguidos, en Laurie Ouellette: "Dream jobs. The glamourization of Beauty Service Work in Media Culture", en Ellias, A. S. - Gill R. - Sharff, Ch. (2017). Aeshetic Labour. Rethinking Beauty Politics in Neolibealism, ). 
tica de la definición de lo real, los discursos que sospechan esos límites o bien intentan obviar ese discurso básico y urgente, o bien lo sustituyen por una ficción literaria, un "cuento maravilloso". En cualquiera de las dos opciones queda borrado todo discurso universitario y crítico, condenándose a actuaciones reproductivas, no productivas, y pensando que su techo son modelos de referencia formales, de los que espigan lo mejor (lo que más gusta), que genera una re-producción manierista.

Desde Kant el arte y la estética se hallan tan cerca de los modos de la moral que algunos diseñadores los confunden. Caen así en un diletantismo generalizado que se revela en una ficción, una sustitución ${ }^{57}$, una legitimación y una espec- tacularización, cualidades todas del postmodernismo como lógica cultural del tardocapitalismo. Por mucho que se lime la aparente brutalidad de este diagnóstico, bien merecería alguna consideración, no para rechazarlo sino para contraargumentarlo, algo más comprometido que las manifestaciones positivas y eufóricas.

Quizás ahora quede más aclarado por qué el título provisional dado a las notas solicitadas tras los primeros premios fuera: Hipertrofia del significante/Transubstanciación del significado/Atrofia del sentido, que sintetiza la impresión recibida por una estética sobresaliente, el escamoteo de un inicio razonable y prometedor por un deseo final artesano y un sentido del mundo concebido desde la alienación. 


\section{Referencias}

AnecA (2004) Libro Blanco. Títulos de Grado en Bellas Artes/Diseño/Restauración. ANECA. Junio 2004.

Bourdieu, P. (2000). Principios de sociología. Istmo. Madrid.

Bonsiepe, G. (2019): "Reflexiones tempestivas sobre el diseño", conferencia: Madrid [www.youtube.com/watch?v=VIJUt7fSDUc]

BAUDRILLARD, J. (1999): El sistema de los objetos. Madrid. Siglo XXI.

- (2006) El complot del arte. Ilusión y desilusión estéticas. Amorrortu. Buenos Aires.

Bauman, Z. , (2002) Modernidad líquida, Fondo de Cultura Económica. Buenos Aires. p. 12.

BÉGout, B. (2007). Zerópolis. Anagrama, Barcelona.

Bonsiepe, G. (2020): "Reflexiones inconclusas" (conferencia) Madrid

Danto, A. C. (1964). «The Artworld», The Journal of Philosophy, 61, pp. 571-584.

Douglas, M. (1996) Cómo piensan las instituciones. Madrid, Alianza Editorial.

Foster, H. (2004). Diseño y delito (y otras diatribas). Akal, Madrid.

FreUd, S. (2013): El malestar en la cultura. Alianza Editorial. Madrid

GadAmer, H.-G. (1988) Verdad y método. Fundamentos de una hermenéutica filosófica. Sígueme. Salamanca.

GonzÁlez Solas, Javier: 2014. "Antes del diseño". Icono 14, Vol. 12, N. ${ }^{\circ} 1$.

- (2020) "Quiebra histórica de la identidad del diseño". III Simposio de la FHD: 'To be or not to be'. El papel del diseño en la construcción de identidades. Museo del Disseny. Barcelona. [http://www.historiadeldisseny.org/wp-content/uploads/La-quiebra-hist\%C3\%B3ricade-la-identidad-del-dise\%C3\%B1o.-JavierGonzalez-Solas..pdf] [14-12-2020].

- (2020) "Grupo 13: Una exposición invisible: 'Publicidad entre el arte y el diseño', I y II" . Questiones Publicitarias, n, ${ }^{\circ}$ 25, pp. 17-26 // n, ${ }^{\circ} 26$, pp. 33-41.

- (2017) "Hipertrofia del significante/Transubstanciación del significado/Atrofia del sentido", Primeros Premios Proyecto Fin de Grado en Diseño Gráfico (no publicado).
— (2012) "El circuito del diseño", Cinco miradas sobre el diseño. JGS. Madrid.

- (2016) "El diseño como industria creativa: una dudosa moneda de cambio". Informe sobre el estado de la cultura en España 2016. Fundación Alternativas.

- (2011). "Lujo tópico y distópico: Un marco para el diseño y la publicidad". Pensar la Publicidad 2011, vol. 5, no 1, 99-120.

- (2001). "Yo confieso. Premios AEPD".Boletín AEPD n० 14 p. 22.

- (2015) "Discutir palabras / discutir posturas. Sobre 'Arte \& Publicidad. La estrategia de la sustitución'. Respuesta a Inmaculada Murcia”. Estudios Filosóficos n. ${ }^{\circ}$ 52. Universidad de Antioquia. Diciembre 2015. pp. 197-202.

HABERMAS, J. (1989) El discurso filosófico de la modernidad, Madrid, Taurus,

HelleR, Á. (1996). Una revisión de la teoría de las necesidades. Barcelona, Paidós Ibérica.

Hofstadter, D. R. (2015) Gödel, Escher, Bach: un eterno y grácil bucle. Tusquets. Barcelona.

JAMESON, F. (2001): El postmodernismo o la lógica cultural del neocapitalismo. Barcelona, Paidós Ibérica.

LAKOFF. G. - JoHnson, M. ((1986): Metáforas de la vida cotidiana. Madrid, Cátedra.

LORÉs, J. (1971)"Grafismo puro, grafismo impuro". Revista CAU. n. ${ }^{\circ} 9$.

LURY, C. (1997) Consumer culture. Cambridge, Polity Press.

MARgolin, V. et al. (2009). Las Rutas del Diseño, México, Designio.

Ministerio de Cultura y Deporte (2018). Plan de fomento de las industrias culturales y creativas 2018.

Prieto, L. (1977). Pertinencia y Práctica. Ensayos de semiología. Gustavo Gili, Barcelona.

UE (2011). Programa Europa Creativa. Consejo de la Unión Europea. Bruselas.

VEGA, E. (2018) Intervención en Jornada Parlamentaria: El diseño español en el siglo XXI. Madrid. https://graffica.info/jornada-sobre-diseno-congreso-de-los-diputados.

Vélez, P. y Calvera, A. (2014). El diseño gráfico:de oficio a profesión (1940-1980). Ajuntament de Barcelona.

ZIZEK, S. (2003). Porque no saben lo que hacen. El goce como un factor político. Paidós 